\title{
First Report of Hepatitis E Virus Infection in Sika Deer in China
}

\author{
Xiao-Xuan Zhang, ${ }^{1,2}$ Si-Yuan Qin, ${ }^{1,2}$ Yuan Zhang, ${ }^{1}$ Qing-Feng Meng, ${ }^{3}$ \\ Jing Jiang, ${ }^{1}$ Gui-Lian Yang, ${ }^{1}$ Quan Zhao, ${ }^{1}$ and Xing-Quan $\mathrm{Zhu}^{2,4}$ \\ ${ }^{1}$ College of Animal Science and Technology, Jilin Agricultural University, Changchun, Jilin 130118, China \\ ${ }^{2}$ State Key Laboratory of Veterinary Etiological Biology, Lanzhou Veterinary Research Institute, \\ Chinese Academy of Agricultural Sciences, Lanzhou, Gansu 730046, China \\ ${ }^{3}$ Jilin Entry-Exit Inspection and Quarantine Bureau, Changchun, Jilin 130000, China \\ ${ }^{4}$ Jiangsu Co-Innovation Center for Prevention and Control of Important Animal Infectious Disease, Yangzhou, Jiangsu 225009, China
}

Correspondence should be addressed to Quan Zhao; zhaoquan0825@163.com and Xing-Quan Zhu; xingquanzhu1@hotmail.com

Received 20 January 2015; Revised 25 March 2015; Accepted 25 March 2015

Academic Editor: Mohamed T. Shata

Copyright ( $\odot 2015$ Xiao-Xuan Zhang et al. This is an open access article distributed under the Creative Commons Attribution License, which permits unrestricted use, distribution, and reproduction in any medium, provided the original work is properly cited.

Hepatitis E virus (HEV), a single stranded RNA, nonenveloped virus, belongs to the genus Hepevirus, in the family of Hepeviridae. In this study, 46 (5.43\%) out of the 847 serum samples from sika deer (Cervus nippon) were detected as seropositive with hepatitis E virus (HEV) by enzyme linked immunosorbent assay (ELISA). These samples were collected from Inner Mongolia and Jilin and Heilongjiang provinces in China, between October 2012 and October 2013. Seroprevalence of HEV infection in male and female deer was $4.82 \%$ and $6.52 \%$, respectively. HEV seroprevalence in sika deer from different geographical locations varied from $3.13 \%$ to $6.73 \%$. There was no significant difference in HEV seroprevalence between sika deer collected in autumn (5.65\%) and winter (4.85\%). This is the first report of HEV seroprevalence in sika deer in China, which will provide foundation information for estimating the effectiveness of future measures to control HEV infection in sika deer in China and assessing the potential risk of humans infected with HEV after consumption of undercooked or raw meat from infected sika deer.

\section{Introduction}

Viral hepatitis is a global health problem [1], especially hepatitis E. HEV is the causative agent of hepatitis E [2]. Hepatitis E virus (HEV), a single stranded RNA, nonenveloped virus, belongs to the genus Hepevirus, in the family of Hepeviridae [2-6]. Previous studies introduced four routes to transmission of HEV. They are fecal-oral transmission, foodborne transmission, transfusion, and vertical transmission [7]. HEV infection can lead to protracted coagulopathy and cholestatis and is also associated with death especially among pregnant women [7-10].

Hepatitis E was first recognized in India in 1978 [5]. Avian HEV and mammalian HEV are major species of hepatitis E virus [5]. More than four genotypes (genotypes $1,2,3$, and 4) have been identified in $\operatorname{HEV}[6,11,12]$; for example, genotypes 1 and 2 of HEV were commonly prevalent in developing countries, and genotype 2 appears to be exclusively anthroponotic, while genotype 1 infects mainly humans but has also been detected in pigs $[13,14]$. Genotype 3 was distributed around the world and could cause severe HEV infection in humans and animals. Most of HEV genotype 4 infections were in Asian countries, and they have been found in humans and pigs [11, 15-18]. Recently, genotype 5 has been proposed as the designation for a variant of HEV isolated from wild boars [12]. Haqshenas et al. [19] and Huang et al. [20] identified a novel HEV strain, which was isolated from chicken, but Avian HEV could not infect nonhuman primates [20]. Humans can be infected by six genotypes of mammalian HEV, namely, types 1 to 4 and two additional genotypes from wild boar [5].

In view of such serious situation, a large number of investigations about HEV have been carried out worldwide [11-27]. In China, infection of HEV has also been reported 


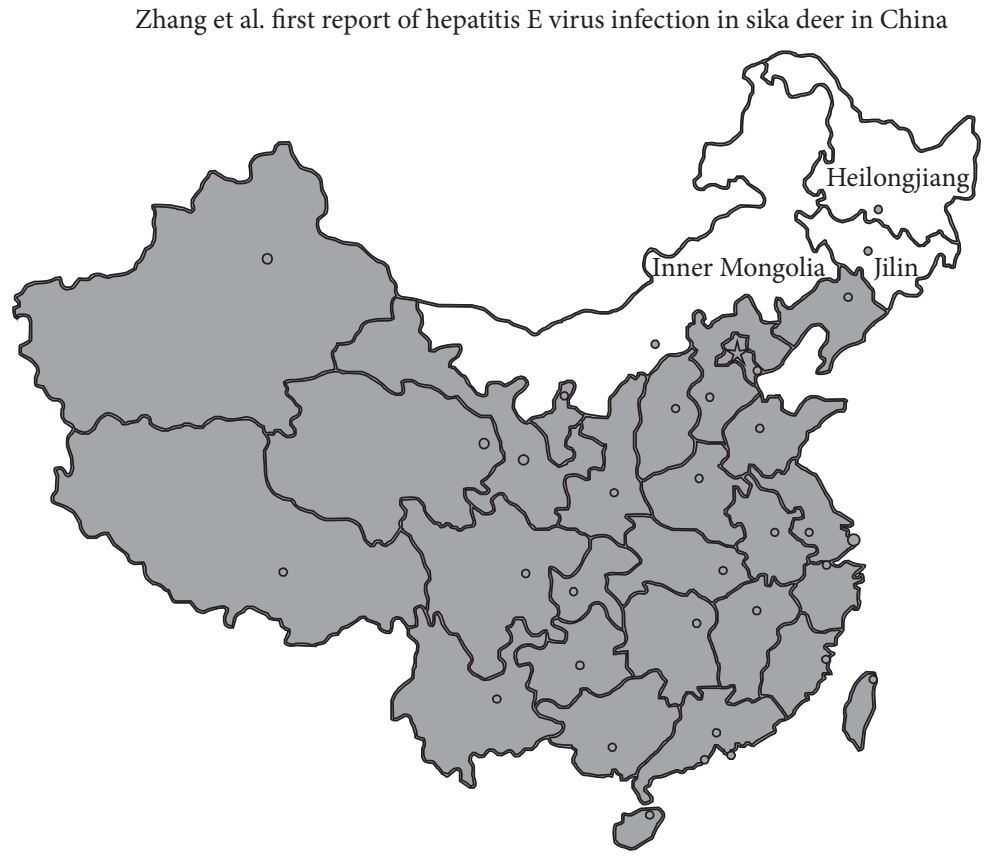

FIGURE 1: Map showing Heilongjiang province, Jilin province, and Inner Mongolia Autonomous Region stranded out in white color in northeastern China, where sika deer serum samples were collected for detection of hepatitis E virus antibodies.

in wild rats, rabbits, pigs, sheep, parrots, chickens, dogs, cats, and humans $[3,29-35]$, but no information was available about HEV infection in sika deer. The objectives of this survey were to investigate the distribution and seroprevalence of HEV infection in sika deer from 4 cities, Northern China, for the first time, provide the "baseline" data for the control of $\mathrm{HEV}$ infection, and assess the potential risk that people are infected by HEV.

\section{Materials and Methods}

2.1. Ethics Statement. This study was approved by the Animal Ethics Committee of Lanzhou Veterinary Research Institute, Chinese Academy of Agricultural Sciences (Approval number LVRIAEC2012-008). The sika deer, from which blood was collected, were handled in accordance with good animal practices required by the Animal Ethics Procedures and Guidelines of the People's Republic of China.

2.2. The Study Site. The samples in this study were collected from 4 cities, Northern China (Figure 1). Changchun $\left(43^{\circ} 05^{\prime} \sim\right.$ $\left.45^{\circ} 15^{\prime} \mathrm{N}, 124^{\circ} 18^{\prime} \sim 127^{\circ} 05^{\prime} \mathrm{E}\right)$ is the capital of Jilin province, and it is one of the central cities in Northeast China and belongs to a semiwet monsoon type zone. Jilin City $\left(42^{\circ} 31^{\prime} \sim 44^{\circ} 40^{\prime} \mathrm{N}\right.$, $125^{\circ} 40^{\prime} \sim 127^{\circ} 56^{\prime} \mathrm{E}$ ) is located in Jilin province, and the climate of Jilin City is northerly continental monsoon type. Harbin $\left(44^{\circ} 04^{\prime} \sim 46^{\circ} 40^{\prime} \mathrm{N}, 125^{\circ} 42^{\prime} \sim 130^{\circ} 10^{\prime} \mathrm{E}\right)$ is one of the central cities in Northeast China and the capital of Heilongjiang province. Harbin belongs to a temperate continental monsoon type climate. Chifeng $\left(41^{\circ} 17^{\prime} 10^{\prime \prime} \sim 45^{\circ} 24^{\prime} 15^{\prime \prime} \mathrm{N}, 116^{\circ} 21^{\prime} 07^{\prime \prime} \sim 120^{\circ} 58^{\prime} 52^{\prime \prime} \mathrm{E}\right)$ is located in the upper reaches of the Xiliao River. Chifeng has a local steppe climate. Sika deer are mostly originated in Changchun, Chifeng, and Harbin in Northern China.

2.3. Serum Samples. All the sika deer blood samples (208 from Harbin city, 316 from Changchun city, 163 from Jilin City, and 160 from Chifeng city) were randomly collected from the 4 cities, Northern China, between October 2012 and October 2013. All the sika deer were bred in the semifree range system. Samples were transported to the laboratory in the College of Animal Science and Technology, Jilin Agriculture University, Jilin province, China. They were kept at $37^{\circ} \mathrm{C}$ for $2 \mathrm{~h}$ and then at $4^{\circ} \mathrm{C}$ for $1 \mathrm{~h}$, and then centrifugation was carried out at $1,000 \times \mathrm{g}$ for $10 \mathrm{~min}$, and the serum was separated and kept at $-20^{\circ} \mathrm{C}$ until further analysis. Information of sika deer about seasons and geographic origin of sampling, gender, and age was recorded.

2.4. Serological Examination. Circulating antibodies (CAb) against HEV were tested by the species-independent doubleantigen sandwich (das) ELISA using a commercially available kit (MP Biomedicals Asia Pacific Pte. Ltd., Singapore) according to the manufacturer's instructions [22]. Positive, negative, and blank controls were supplied in the kit and set in each test.

2.5. Statistical Analysis. The differences of seroprevalence of $\mathrm{HEV}$ infection in sika deer from different locations, gender, and seasons were analyzed statistically using SAS software (version 9.1, SAS Institute, Inc., Cary, NC) [36]. Results were considered statistically significant if $P<0.05$. Odds ratios (OR) and their 95\% confidence interval (95\% CI) were provided in this study. 
TABLE 1: Seroprevalence of hepatitis E virus (HEV) infection in sika deer (Cervus nippon) in different region, gender, and season by enzyme linked immunosorbent assay (ELISA).

\begin{tabular}{|c|c|c|c|c|c|c|}
\hline Variable & Category & $\begin{array}{c}\text { Number of } \\
\text { examined deer }\end{array}$ & $\begin{array}{c}\text { Number of } \\
\text { positive deer }\end{array}$ & Prevalence (\%) $(95 \% \mathrm{CI})$ & $P$ value & OR $(95 \% \mathrm{CI})$ \\
\hline \multirow{2}{*}{ Gender } & Male & 540 & 26 & $4.82(3.01-6.62)$ & \multirow{2}{*}{0.29} & Reference \\
\hline & Female & 307 & 20 & $6.52(3.75-9.28)$ & & $1.38(0.76-2.51)$ \\
\hline \multirow{4}{*}{ Region } & Harbin & 208 & 14 & $6.73(3.33-10.14)$ & \multirow{4}{*}{0.36} & Reference \\
\hline & Changchun & 316 & 20 & $6.33(3.64-9.01)$ & & $0.94(0.46-1.90)$ \\
\hline & Jilin City & 163 & 7 & $4.29(1.18-7.41)$ & & $0.62(0.25-1.58)$ \\
\hline & Chifeng & 160 & 5 & $3.13(0.43-5.82)$ & & $0.45(0.16-1.27)$ \\
\hline \multirow{2}{*}{ Season } & Autumn & 620 & 35 & $5.65(3.83-7.46)$ & \multirow{2}{*}{0.65} & Reference \\
\hline & Winter & 227 & 11 & $4.85(2.05-7.64)$ & & $0.85(0.43-1.71)$ \\
\hline Total & & 847 & 46 & $5.43(3.91-6.96)$ & & \\
\hline
\end{tabular}

TABLE 2: Prevalence of hepatitis E virus (HEV) infection in deer around the world.

\begin{tabular}{|c|c|c|c|c|c|c|}
\hline Country & Species & Test $^{\mathrm{a}}$ & Number of tested deer & Positive (\%) & Year $^{\mathrm{b}}$ & Reference \\
\hline Poland & Red deer (Cervus elaphus) & ELISA & 118 & 0 & $2012-2013$ & {$[21]$} \\
\hline Poland & Roe deer (Capreolus capreolus) & ELISA & 38 & 0 & $2012-2013$ & {$[21]$} \\
\hline Poland & Fallow deer (Dama dama) & ELISA & 5 & 0 & $2012-2013$ & {$[21]$} \\
\hline Poland & Sika deer (Cervus nippon) & ELISA & 4 & 0 & $2012-2013$ & {$[21]$} \\
\hline Netherlands & Red deer & ELISA & 38 & 5 & $2005-2008$ & {$[22]$} \\
\hline Netherlands & Red deer & RT-PCR & 39 & 15 & $2005-2008$ & {$[22]$} \\
\hline Japan & Deer & ELISA & 117 & 2 & 2003-2004 & {$[23]$} \\
\hline USA & Wild sika deer & ELISA & 174 & 0 & $\mathrm{UN}$ & {$[24]$} \\
\hline Japan & Wild sika deer & ELISA & 976 & 2.6 & $\mathrm{UN}$ & {$[25]$} \\
\hline Japan & Wild sika deer & RT-PCR & 247 & 0 & $\mathrm{UN}$ & {$[26]$} \\
\hline Japan & Yezo deer & ELISA & 520 & 34.8 & UN & {$[26]$} \\
\hline Japan & Yezo deer & WB & 520 & 2.8 & UN & {$[26]$} \\
\hline Spain & Red deer & ELISA & 968 & 10.4 & 2000-2009 & {$[27]$} \\
\hline Spain & Red deer & RT-PCR & 968 & 13.6 & 2000-2009 & {$[27]$} \\
\hline Hungary & Roe deer & RT-PCR & 32 & 34.4 & 2001-2006 & {$[28]$} \\
\hline
\end{tabular}

${ }^{a}$ ELISA: enzyme-linked immunosorbent assay; RT-PCR: reverse transcription polymerase chain reaction; WB: Western blot.

${ }^{\mathrm{b}} \mathrm{UN}$ : unknown.

\section{Results}

A total of 46 (5.43\%, 95\% confidence interval (CI) 3.91-6.96) out of 847 sika deer were detected as seropositive of HEV by ELISA (Table 1). Seroprevalence of HEV in male deer was $4.82 \%$ (95\% CI 3.01-6.62), which was lower than that in female deer $(6.52 \%, 95 \%$ CI 3.75-9.28), but the difference was not statistically significant $(P>0.05)$. HEV seroprevalence in sika deer from different geographical locations varied from $3.13 \%$ (95\% CI $0.43-5.82$ ) to $6.73 \%$ (95\% CI 3.33-10.14), but the difference was not statistically significant among the different regions $(P>0.05)$. Sika deer collected in winter $(4.85 \%, 95 \%$ CI $2.05-7.64, P>0.05)$ had a slightly lower HEV seroprevalence compared to sika deer collected in autumn (5.65\%, 95\% CI 3.83-7.46), and the difference was not significant statistically.

\section{Discussion}

There are many reports showing that HEV could infect deer all over the world (Table 2). In the present study, we surveyed the HEV seroprevalence in sika deer at 4 cities in Northern China. The overall HEV seroprevalence in sika deer was $5.43 \%$, which was lower than that in red deer (Cervus elaphus) in Spain (10.4\%) [27] and Yezo deer in Japan (34.8\%) [26] by ELISA and in red deer in Spain (13.6\%) [27] and Netherlands (15\%) [22] and roe deer in Hungary (34.4\%) [28] by RT-PCR but higher than that in red deer in Netherlands (5\%) [22] and wild sika deer in Japan (2.6\%) [25] and USA (0\%) [7] by ELISA and in wild sika deer in Japan by RT-PCR (0\%) [25] and Western blot (2.8\%) [26] (Table 2). It is well known that due to high discordance between assays in different detection methods, the actual discrepancy is difficult to explain in the prevalence of HEV among different studies. The differences may also be due to the investigated areas that challenged the survival of $\mathrm{HEV}$, the differences in sanitation, animal-welfare for deer, animal husbandry practices, and geographical and ecological factors, for example, rainfall.

Previous studies $[29,37]$ demonstrated the male has the higher positive rates than the female, but the present study indicates the opposite although the difference in prevalence 
between females and males is not statistically significant (Table 1). In different regions group, HEV seroprevalence in sika deer varied from $3.13 \%(5 / 160)$ to $6.73 \%$ (14/208). Sika deer in Harbin has the highest HEV seroprevalence, followed by Changchun, the third was Jilin City, and Chifeng was the last, but the difference was not statistically significant $(P=$ 0.36) (Table 1). Climate, geography, degree of environment contamination with HEV, ecological conditions, feeding conditions, and animal welfares could be the reasons for the differences in HEV seroprevalence in sika deer in different cities.

In terms of the sampling seasons, HEV seroprevalence in sika deer collected in autumn was $5.65 \%$, which was higher than that collected in winter (4.85\%), but the difference was not statistically significant $(P=0.65)$ (Table 1$)$. This may happen because in autumn the local climate was suitable for the survival of HEV and the resistance of sika deer was improved in winter in four cities. Compared with autumn, sika deer has a small range of activities and the relatively lower exposure of $\mathrm{HEV}$ in winter.

Sika deer are popular in China, and they are famous for medicinal value. Velvet antlers, blood, and meat are the main products from sika deer. Deer meat especially was widely recognized by most people with the improvement of living standards in Northern China. A study has shown that HEV could be transmitted from deer to humans [37], so sika deer is considered as the potential source for the spread of HEV to humans, but, in this study, we did not demonstrate that the elder have higher HEV seroprevalence than the younger [38] because the samples were collected in four cities in northern China between October 2012 and October 2013, just including autumn and winter samples, and the animals were adult sika deer, so our results may have not reflected the relationship between HEV seroprevalence and age. Moreover, the study only detected the antibodies against HEV in sika deer, and no sequence information was obtained due to limited volume of serum, so it could not reflect the true infection rate. Further studies should be conducted to get sequence information to confirm the real HEV infection rates and to determine the HEV genotypes.

\section{Conclusion}

The present investigation suggests the existence of HEV infection in sika deer, Northern China. The result may provide fundamental information for estimating the effectiveness of future measure to control HEV infection in sika deer in China and assessing the potential risk of humans infected by HEV.

\section{Conflict of Interests}

All the authors declare no conflict of interests.

\section{Authors' Contribution}

Xiao-Xuan Zhang and Si-Yuan Qin contributed equally to this work.

\section{Acknowledgments}

This study was supported by the Key Scientific and Technological Project of Jilin Province (Grant no. 20140204068NY) and the Science Fund for Creative Research Groups of Gansu Province (Grant no. 1210RJIA006).

\section{References}

[1] J. Khan, M. Shafiq, S. Mushtaq et al., "Seropositivity and coinfection of hepatitis B and C among patients seeking hospital care in Islamabad, Pakistan," BioMed Research International, vol. 2014, Article ID 516859, 4 pages, 2014.

[2] S. A. Rutjes, M. Bouwknegt, J. W. van der Giessen, A. M. de Roda Husman, and C. B. E. M. Reusken, "Seroprevalence of hepatitis e virus in pigs from different farming systems in the Netherlands," Journal of Food Protection, vol. 77, no. 4, pp. 640-642, 2014.

[3] X.-X. Zhang, N.-Z.Zhang, D.-H. Zhou, W.-P. Tian, Y.-T. Xu, and X.-Q. Zhu, "Seroprevalence of hepatitis E virus in four species of parrots in China," Pakistan Veterinary Journal, vol. 34, no. 1, pp. 130-132, 2014.

[4] W. F. El-Tras, A. A. Tayel, and N. N. El-Kady, "Seroprevalence of hepatitis E virus in humans and geographically matched food animals in Egypt," Zoonoses and Public Health, vol. 60, no. 3, pp. 244-251, 2013.

[5] M. S. Khuroo, "Discovery of hepatitis E: the epidemic nonA, non-B hepatitis 30 years down the memory lane," Virus Research, vol. 161, no. 1, pp. 3-14, 2011.

[6] I. K. Mushahwar, "Hepatitis E virus: molecular virology, clinical features, diagnosis, transmission, epidemiology, and prevention," Journal of Medical Virology, vol. 80, no. 4, pp. 646-658, 2008.

[7] B. Xu, H. B. Yu, W. Hui et al., "Clinical features and risk factors of acute hepatitis E with severe jaundice," World Journal of Gastroenterology, vol. 18, no. 48, pp. 7279-7284, 2012.

[8] T. N. Chau, S. T. Lai, C. Tse et al., "Epidemiology and clinical features of sporadic hepatitis $\mathrm{E}$ as compared with hepatitis A," The American Journal of Gastroenterology, vol. 101, no. 2, pp. 292296, 2006.

[9] C. Renou, V. Gobert, C. Locher et al., "Prospective study of Hepatitis E Virus infection among pregnant women in France," Virology Journal, vol. 11, no. 1, article 68, 2014.

[10] Y. Song, W. Park, B. Park et al., "Hepatitis E virus infections in humans and animals," Clinical and Experimental Vaccine Research, vol. 3, no. 1, pp. 29-36, 2014.

[11] G. G. Schlauder and I. K. Mushahwar, "Genetic heterogeneity of hepatitis E virus," Journal of Medical Virology, vol. 65, no. 2, pp. 282-292, 2001.

[12] M. Takahashi, T. Nishizawa, H. Sato, Y. Sato, S. Nagashima, and H. Okamoto, "Analysis of the full-length genome of a Hepatitis E virus isolate obtained from a wild boar in Japan that is classifiable into a novel genotype," Journal of General Virology, vol. 92, no. 4, pp. 902-908, 2011.

[13] J. E. Arends, V. Ghisetti, W. Irving et al., "Hepatitis E: an emerging infection in high income countries," Journal of Clinical Virology, vol. 59, no. 2, pp. 81-88, 2014.

[14] A. Ahmed, I. A. Ali, H. Ghazal, J. Fazili, and S. Nusrat, "Mystery of hepatitis e virus: recent advances in its diagnosis and management," International Journal of Hepatology, vol. 2015, Article ID 872431, 6 pages, 2015. 
[15] X. J. Meng, P. G. Halbur, M. S. Shapiro et al., "Genetic and experimental evidence for cross-species infection by swine hepatitis E virus," Journal of Virology, vol. 72, no. 12, pp. 97149721, 1998.

[16] L. Lu, C. Li, and C. H. Hagedorn, "Phylogenetic analysis of global hepatitis E virus sequences: genetic diversity, subtypes and zoonosis," Reviews in Medical Virology, vol. 16, no. 1, pp. 536, 2006.

[17] F. R. Lorenzo, B. Tsatsralt-Od, S. Ganbat, M. Takahashi, and H. Okamoto, "Analysis of the full-length genome of hepatitis E virus isolates obtained from farm pigs in Mongolia," Journal of Medical Virology, vol. 79, no. 8, pp. 1128-1137, 2007.

[18] H. Okamoto, "Genetic variability and evolution of hepatitis E virus," Virus Research, vol. 127, no. 2, pp. 216-228, 2007.

[19] G. Haqshenas, H. L. Shivaprasad, P. R. Woolcock, D. H. Read, and X. J. Meng, "Genetic identification and characterization of a novel virus related to human hepatitis E virus from chickens with hepatitis-splenomegaly syndrome in the United States," The Journal of General Virology, vol. 82, no. 10, pp. 2449-2462, 2001.

[20] F. F. Huang, Z. F. Sun, S. U. Emerson et al., "Determination and analysis of the complete genomic sequence of avian hepatitis $\mathrm{E}$ virus (avian HEV) and attempts to infect rhesus monkeys with avian HEV," The Journal of General Virology, vol. 85, no. 6, pp. 1609-1618, 2004.

[21] M. Larska, M. K. Krzysiak, A. Jabłoński, J. Kesik, M. Bednarski, and J. Rola, "Hepatitis E virus antibody prevalence in wildlife in Poland," Zoonoses and Public Health, vol. 62, no. 2, pp. 105-110, 2015.

[22] S. A. Rutjes, F. Lodder-Verschoor, W. J. Lodder et al., "Seroprevalence and molecular detection of hepatitis E virus in wild boar and red deer in The Netherlands," Journal of Virological Methods, vol. 168, no. 1-2, pp. 197-206, 2010.

[23] H. Sonoda, M. Abe, T. Sugimoto et al., "Prevalence of hepatitis $\mathrm{E}$ virus (HEV) infection in wild boars and deer and genetic identification of a genotype 3 HEV from a boar in Japan," Journal of Clinical Microbiology, vol. 42, no. 11, pp. 5371-5374, 2004.

[24] C. Yu, C. Zimmerman, R. Stone et al., "Using improved technology for filter paper-based blood collection to survey wild Sika deer for antibodies to hepatitis E virus," Journal of Virological Methods, vol. 142, no. 1-2, pp. 143-150, 2007.

[25] Y. Matsuura, M. Suzuki, K. Yoshimatsu et al., "Prevalence of antibody to hepatitis e virus among wild sika deer, Cervus nippon, in Japan," Archives of Virology, vol. 152, no. 7, pp. 13751381, 2007.

[26] D. Tomiyama, E. Inoue, Y. Osawa, and K. Okazaki, "Serological evidence of infection with hepatitis e virus among wild Yezodeer, Cervus nippon yesoensis, in Hokkaido, Japan," Journal of Viral Hepatitis, vol. 16, no. 7, pp. 524-528, 2009.

[27] M. Boadella, M. Casas, M. Martín et al., "Increasing Contact with hepatitis E virus in red deer, Spain," Emerging Infectious Diseases, vol. 16, no. 12, pp. 1994-1996, 2010.

[28] G. Reuter, D. Fodor, P. Forgách, A. Kátai, and G. Szucs, "Characterization and zoonotic potential of endemic hepatitis E virus (HEV) strains in humans and animals in Hungary," Journal of Clinical Virology, vol. 44, no. 4, pp. 277-281, 2009.

[29] W. Li, D. Guan, J. Su et al., "High prevalence of rat hepatitis E virus in wild rats in China," Veterinary Microbiology, vol. 165, no. 3-4, pp. 275-280, 2013.

[30] S. Wang, C. Dong, X. Dai et al., "Hepatitis E virus isolated from rabbits is genetically heterogeneous but with very similar antigenicity to human HEV,' Journal of Medical Virology, vol. 85, no. 4, pp. 627-635, 2013.

[31] X. J. Wang, Q. Zhao, F. L. Jiang et al., "Genetic characterization and serological prevalence of swine hepatitis E virus in Shandong province, China," Veterinary Microbiology, vol. 172, no. 34, pp. 415-424, 2014.

[32] J.-Y. Wu, Q. Kang, W.-S. Bai, and Z.-H. Bai, "Seroepidemiological survey of sheep hepatitis E virus infection in Aksu region of Xinjiang Autonomous," Chinese Journal of Virology, vol. 26, no. 3, pp. 234-237, 2010 (Chinese).

[33] Q. Zhao, E. M. Zhou, S. W. Dong et al., "Analysis of avian hepatitis E virus from chickens, China," Emerging Infectious Diseases, vol. 16, no. 9, pp. 1469-1472, 2010.

[34] H. Liang, J. Chen, J. Xie et al., "Hepatitis E virus serosurvey among pet dogs and cats in several developed cities in China," PLoS ONE, vol. 9, no. 6, Article ID e98068, 2014.

[35] X. Dai, C. Dong, Z. Zhou et al., "Hepatitis E virus genotype 4, Nanjing, China, 2001-2011," Emerging Infectious Diseases, vol. 19, no. 9, pp. 1528-1530, 2013.

[36] L. Zhang, H. Liu, B. Xu et al., "Rural residents in China are at increased risk of exposure to tick-borne pathogens anaplasma phagocytophilum and ehrlichia chaffeensis," BioMed Research International, vol. 2014, Article ID 313867, 11 pages, 2014.

[37] S. Tei, N. Kitajima, S. Ohara et al., "Consumption of uncooked deer meat as a risk factor for hepatitis $\mathrm{E}$ virus infection: an age- and sex-matched case-control study," Journal of Medical Virology, vol. 74, no. 1, pp. 67-70, 2004.

[38] C. G. Teo, "Much meat, much malady: changing perceptions of the epidemiology of hepatitis E," Clinical Microbiology and Infection, vol. 16, no. 1, pp. 24-32, 2010. 


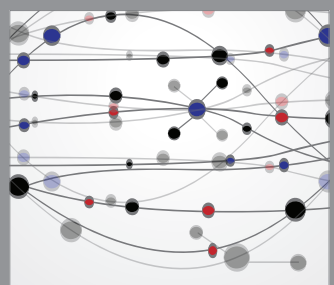

The Scientific World Journal
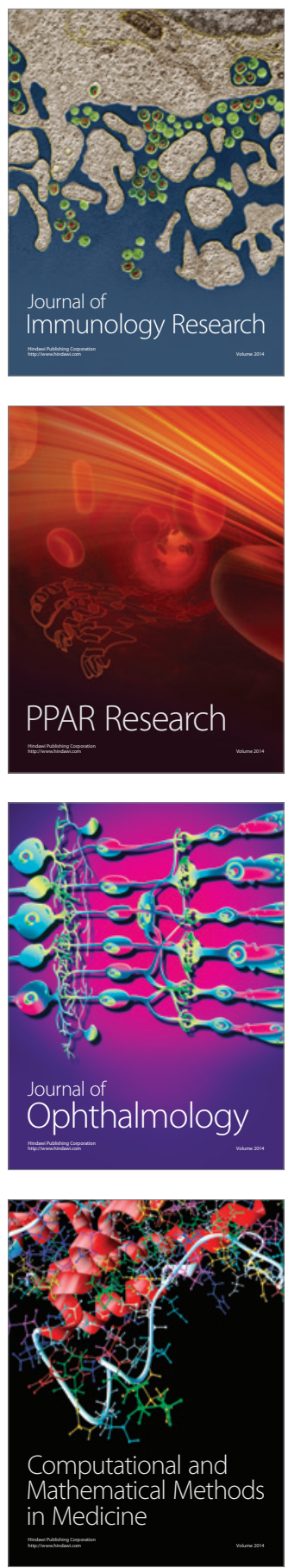

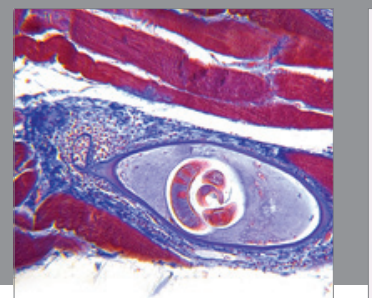

Gastroenterology

Research and Practice
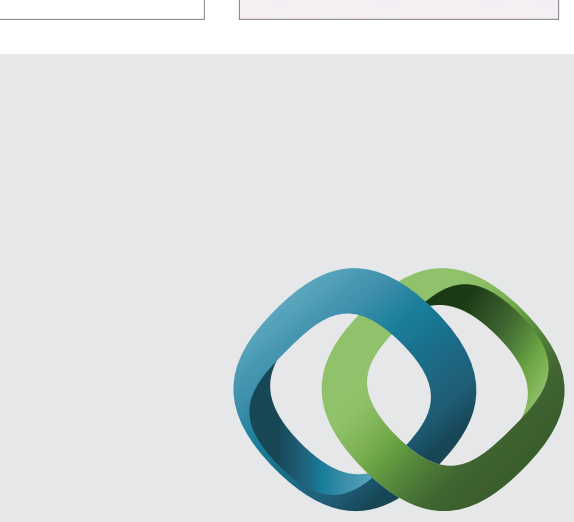

\section{Hindawi}

Submit your manuscripts at

http://www.hindawi.com
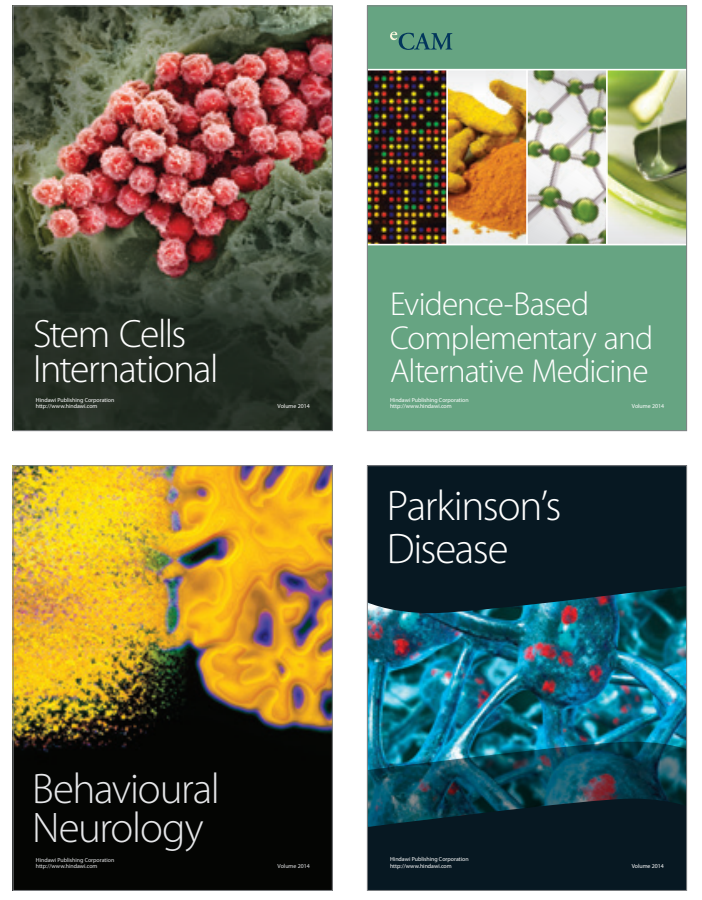
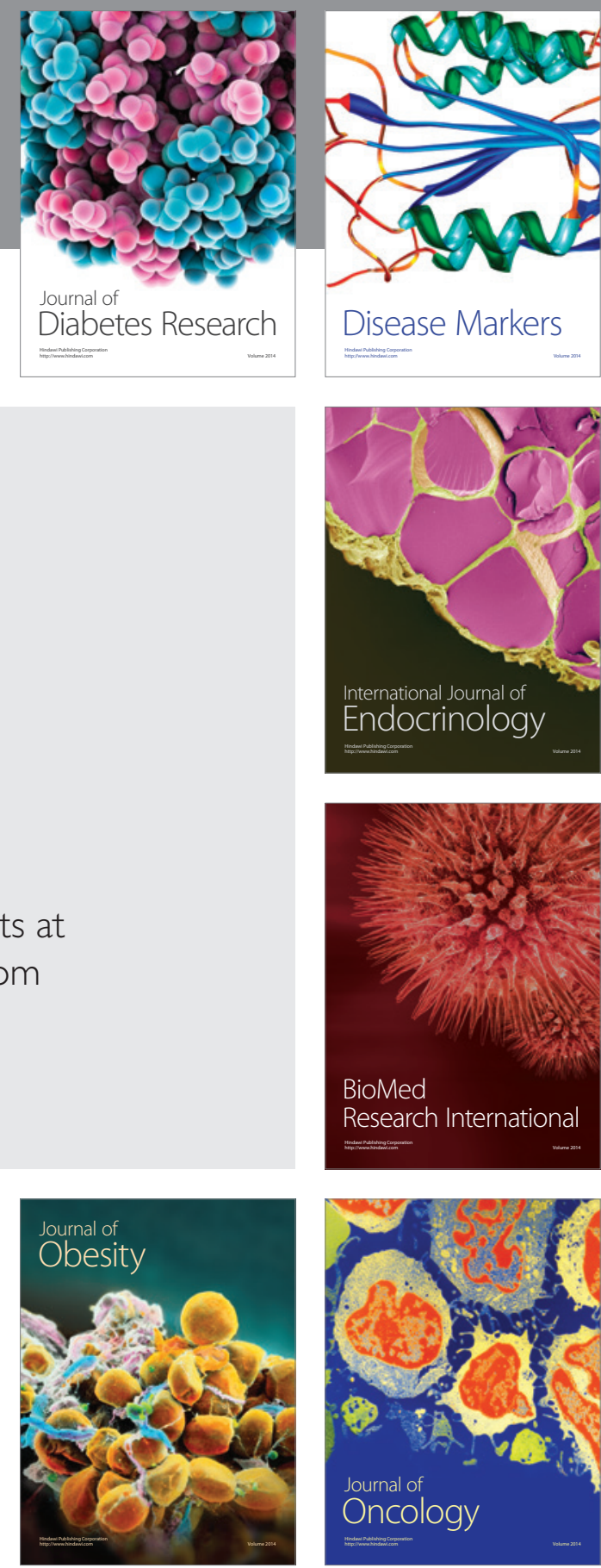

Disease Markers
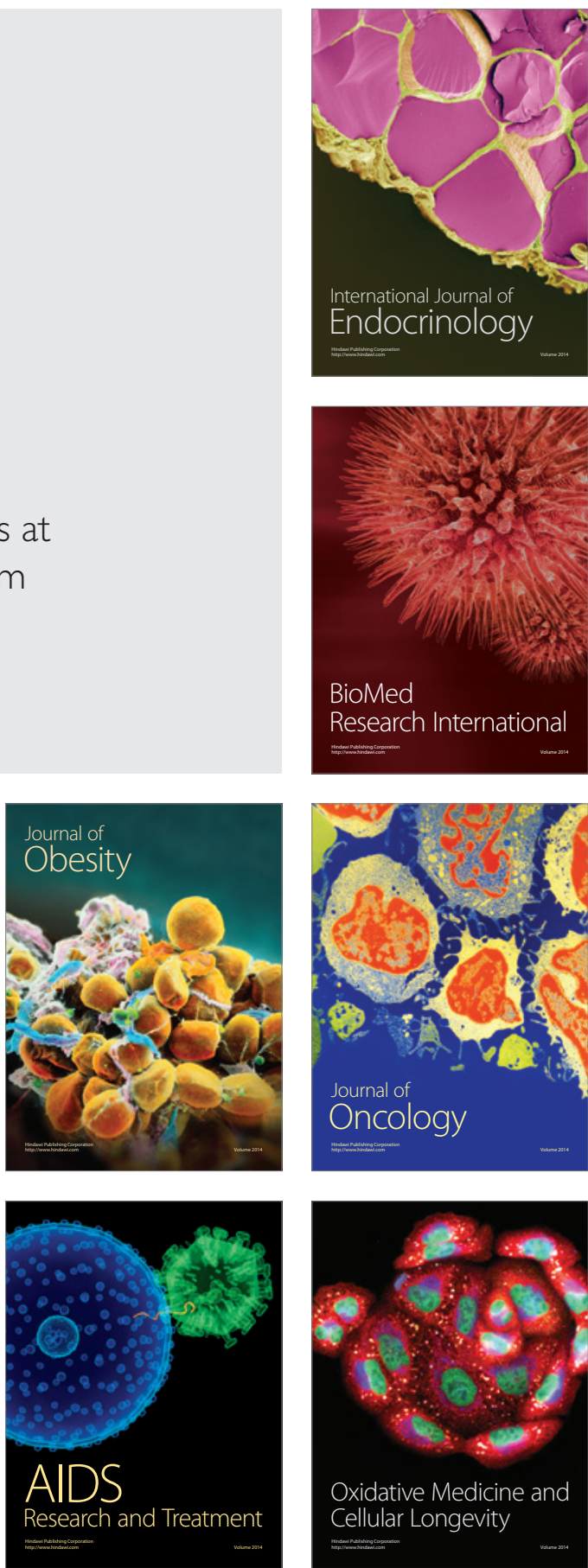